\title{
Experimental and Numerical Study of Super-Critical Flow Around the Rough Sphere
}

\author{
Suzana Linić ${ }^{1)}$ \\ Slavica Ristić ${ }^{1)}$ \\ Zoran Stefanović ${ }^{2)}$ \\ Mirko Kozic ${ }^{3)}$ \\ Goran Ocokoljić ${ }^{3)}$
}

\begin{abstract}
This paper presents the experimental and numerical research on the sphere model with the goal of prediction of a flow behaviour in a presence of the surface roughness. Results indicate the problems and suggest the solution for engineering practice. The similarity of the numerical and wind tunnel flows was reached by an application of a combination of the intentionally introduced turbulence intensity in a numerical flow as well the artificial roughness of the model, for a reason of restricted requirements of the turbulence modelling.
\end{abstract}

Key words: aerodynamics, wind tunnel, numerical simulation, sphere, rough surface, fluid flow.

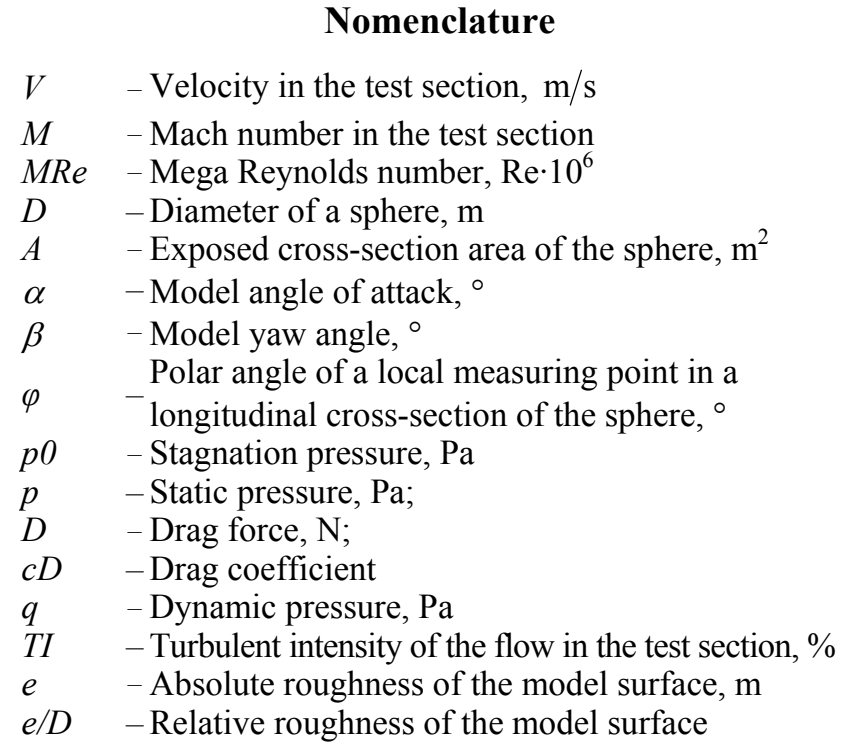

Introduction

$\mathrm{T}$ he aim of this work was to explore the possibility of prediction of the flow and drag coefficient behaviour of the rough sphere, and hence to somewhat support solving similar problems in practice, like those linked to small continual surface damages. The continual surface damages may be in a form of low-height roughness created by corrosion, erosion, even dirt rose over the external wetted surfaces or unreachable flow zones. Characteristic for these types of surfaces is the fact that such small imperfections, if they are out of the bounds of heights that are considered as aerodynamically smooth, could not be modelled.
The test model was selected to be a sphere, a fundamental test body, commonly used for a subsonic wind tunnel flow quality measurement and assessment of the wind tunnel turbulence factor. The sphere was in a focus of many researchers even since the early findings, from the XVII century, in the field of fluid mechanic as noted in the review of experimental tests of the sphere by Riabouchinsky [1] and later Krumins [2], who collected aerodynamic characteristics of the smooth sphere in subsonic and supersonic flows, as a function of the Reynolds and Mach numbers and various other effects. The sphere's aerodynamic sensitivity to the flow character due to the Reynolds number variations and the surface roughness were theoretically considered by A. F. Zxhm [3] and experimentally tested and described among first by Wieselsberger [4], Schlichting [5], Achenbach [6, 7], and after Batchelor [8], Hoerner [9], with the purpose to standardize and correlate test results from the wind tunnels.

Nowadays, researchers (Constantinescu et al. [10, 11], Jones and Clarke [12]) find convenient to predict the flow by the computational fluid dynamics (CFD), but in a number they treated the cases in a range of low Reynolds numbers. A flow past sphere at moderate and high Reynolds numbers were numerically explored by Fornberg [4] and Achenbach $[6,7]$. As well, the exploring of the rough spheres was implemented in the field of aerodynamics of the sport balls by Mehta and Pallis [14], Cross [15] and Kensrud [16]. However, the CFD solutions need the validation through the wind tunnel experiments, as well as the visualizations, which were presented by Taneda [17] and Cross [18].

In the VTI wind tunnels the sphere is included in various experiments, both for the pressure and force measurements, the flow quality, as well the imaging by the optical and nonoptical techniques. The purpose of the non-optical flow

\footnotetext{
1) Institute Gosa, Milana Rakica 35, 11000 Belgrade, SERBIA

2) University of Belgrade, Faculty of Mechanical Engineering, Kraljice Marije 16, 11020 Belgrade 35, SERBIA

3) Military Technical Institute (VTI), Ratka Resanovića 1, 11132 Belgrade, SERBIA

Correspondence to: Suzana Linić; e-mail: sumonja@yahoo.com
} 
visualizations, in this work given around the sphere, is a verification of the experimental data measurement while, described by Ristic [19-22]; the optical visualization techniques are able to determine quantitative values of the flow parameters either of the flow around the sphere or in the complex flow, such is in the axial fan [23].

Anderson and Uhlherr [24] explored one of the influenced factors, the roughness, to the flow quality and the drag coefficient level. Nowadays, researchers present the experimental methods of the "smart morphable" model surfaces with the intention to control the aerodynamic drag [25].

The gates for new solutions in a field of turbulent flow over the rough surfaces, especially the sphere, are still open because the reported results in all had also many others influenced factors which made the flow over the sphere the complex problem, in the range of critical and super-critical regimes in digression to a simple design.

In this work the aerodynamic sensitivity of a sphere is represented through the numerically obtained aerodynamic drag coefficients and the flow field compared to those obtained in the VTI wind tunnel testing.

The well-known problems, connected to the flow over the rough sphere, are presented for the practical use of the research and numerical simulations. Here the attention is put on the overall drag coefficient, in a low turbulent stream, rather than the flow behavior in a wake, as well as its time dependence. Thus, the intention is to define a valuable method and experience for implementing it to the tasks like being a high-speed train experiment design or testing of the ventilation mill's elements of the thermal plant.

\section{Flow Over a Sphere and the Influence Factors}

Following the drag coefficient values, from the almost motionless to $M R e=1$, the phases of a characteristic flow behavior are followed from one to another (Fig.1). The flow at very low $M R e$ is creep with no separation. Afterwards, the laminar flow regime is present, up to $M R e \approx 0.3$, characterized with the laminar boundary layer, early separation and a wide wake. Viewing the sub-critical region close to a critical, the separation position is $\varphi \approx 80^{\circ}$, in a range $\mathrm{MRe} \approx 0.05-0.16$ and from here with $M R e$ growing up to 0.25 the separation point is moving downstream, to $\varphi \approx 90^{\circ}$, and continues in the same manner to a value of about $108^{0}$, at $M R e \approx 0.3$, according to the experiments made by Achenbach, after which the separation point holds the stabile position at $\varphi \approx 120^{\circ}$. From the point $M R e \approx 0.3$ the critical regime begins, during which with $M R e$ is growing to end regime value of about 0.4 , the drag coefficient suddenly decreased from about 0.47 to 0.06 , passing the critical value of 0.3 at $M R e=0.385$. Over the critical flow regime, the flow transforms and here the turbulent boundary layer impacts a delayed separation as well as shrinking in the wake. In the super-critical regime, the pressure is recovering, the flow in the wake becomes more organized and the drag coefficient is increased. Results reported by Achenbach are tracing the phenomenon, but they did not report all the test details like the turbulence level was needed for CFD validation.

The turbulent flow shows similar behaviour if it is streaming over the rough sphere, depending on the rough height (described in a form of a relative roughness related to the sphere diameter). One may note that the influence of the model roughness may be ignored for laminar flows. Achenbach [7] reported that with the increase of the relative roughness the pre-critical and critical regimes begin earlier and the drag coefficient drop is less than for the smooth sphere. Furthermore, the separation point movement with Reynolds number variations has a milder trend of increasing but in values - smaller. For example, if the roughness is $e / D=0.0025$, a critical drag value of $c_{D_{\text {critical }}}=0.3$ occurs at $M R e \approx 0.13$, with a corresponding value of $\varphi \approx 112^{0}$, while the separation occurs later, $\varphi \approx 120^{\circ}$ at a very beginning of the super-critical regime.

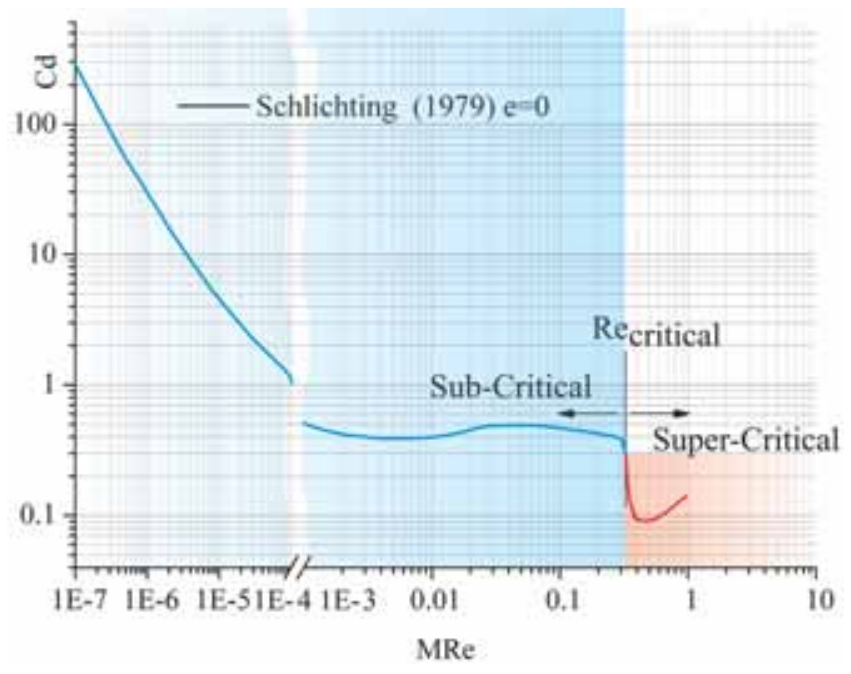

Figure 1. Drag coefficient of the sphere vs $M R e$ of a free stream by Schlichting [5]

Significant flow phenomenon, either in the wind tunnel or numerical simulations, is the turbulence intensity, Tu. Just because the sphere is highly sensitive to the flow regimes it is used for the examination of the flow quality in the wind tunnels. This featured influenced parameter impacts on the flow over the sphere changing the drag coefficient function against the Reynolds number. If the wind tunnel characteristic turbulence intensity, for a certain operating regime, is higher, the resulting aerodynamically smooth sphere critical drag regime will be displaced to a lower range of the Reynolds numbers, even if a very small difference to free air exists. Thus, one may experience the false respond in case of a low flow quality in the wind tunnel.

The combination of irregularities and surface quality of the model shape, as well as the wind tunnel flow quality, is experimental reality about which the special care is always taken to keep the resulting errors as low as possible.

On the contrary, to reach the requirements of the flow similarities of the model and a prototype, the turbulence may be intentionally introduced for special requirements. For the purpose of the inlet or local turbulence creation various additional devices are introduced. Meshes over the entire cross section of the test section are producing the artificial turbulence over the smooth model. Impediments may be placed over the model surfaces, locally as strips of Carburundum or wires, at a position of assumed flow separation point acting on the following flow and pressure distribution or spread all over the wetted model surface. A successful combination in the experiment is one that closely represents the flow similar to real case of a prototype and that is a target, the best guarantee to prediction of the prototype aerodynamic characteristics.

The idea of introducing the roughness and the turbulence intensity is used also in the numerical simulations for reaching the similar flow quality over the model for complex problems. In this research, the intentionally introduced variable turbulence intensity and the sphere roughness, are used with the purpose of prediction of the wind tunnel results of CFD and thus help in solving other similar problems. In a frame of 
the available resources and time, the obtained results gave a very good prediction and correspondence.

\section{Wind tunnel test of the sphere}

Experimental studies of the sphere were done in a large subsonic wind tunnel, T-35, at the VTI Experimental Aerodynamic Division. Through the standard flow quality procedure the pressure sphere test was also performed, after some modifications of the facility and the model was subject to force/moments and pressure measurements as well as the flow visualization.

The large subsonic wind tunnel, T-35, is a closed circuit, continual type of the wind tunnel with the octagonal test section ( $4.4 \mathrm{~m}$ wide, $3.2 \mathrm{~m}$ high and $5.5 \mathrm{~m}$ long). The cross section area of the test section is $11.93 \mathrm{~m}^{2}$. In this study the test section with a sting model support system was used. For this wind tunnel configuration the experiments may be run in a range of $M=0.1-0.52$, in the test section, while only an axial fan is used, and in a range of $M=0.52-0.8$ if the injector system aids the fan by pressurization of the inflow, up to 1.52 bars of stagnation pressure. Operational envelope in a fan-only regime is achieved by varying the RPM of the fan and a blade pitching angle, keeping stagnation pressure on the atmospheric level, while by using the injector system the pressure is added for achieving the highest capacity. In Figures $2 \mathrm{a}$ and $2 \mathrm{~b}$ the wind tunnel T-35 sketch is presented.

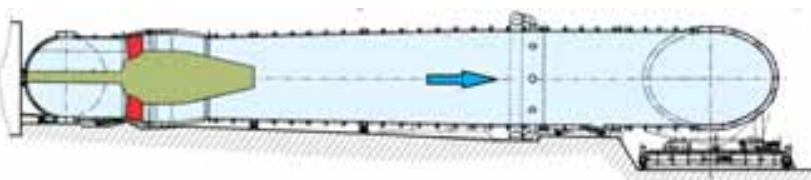

(a)

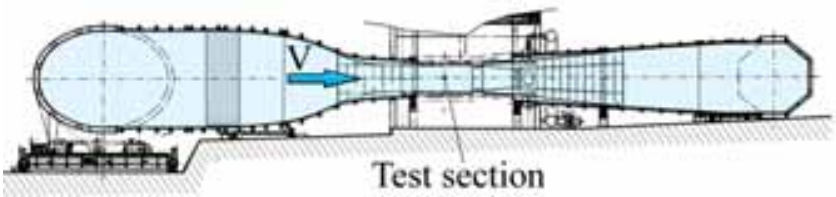

(b)

Figure 2. Wind tunnel T-35 cross-sections along the large diffuser (a) and the test section (b)

The test model was the pressure sphere, Fig.3, manufactured of duraluminium in a diameter of $110 \mathrm{~mm}$, mirror-polished. The sphere was mounted in the centre of the test section by the sting, $38 \mathrm{~mm}$ in diameter, via adapter to a model support strut (Fig.4). The sting and the sphere were placed in zero incidence position.

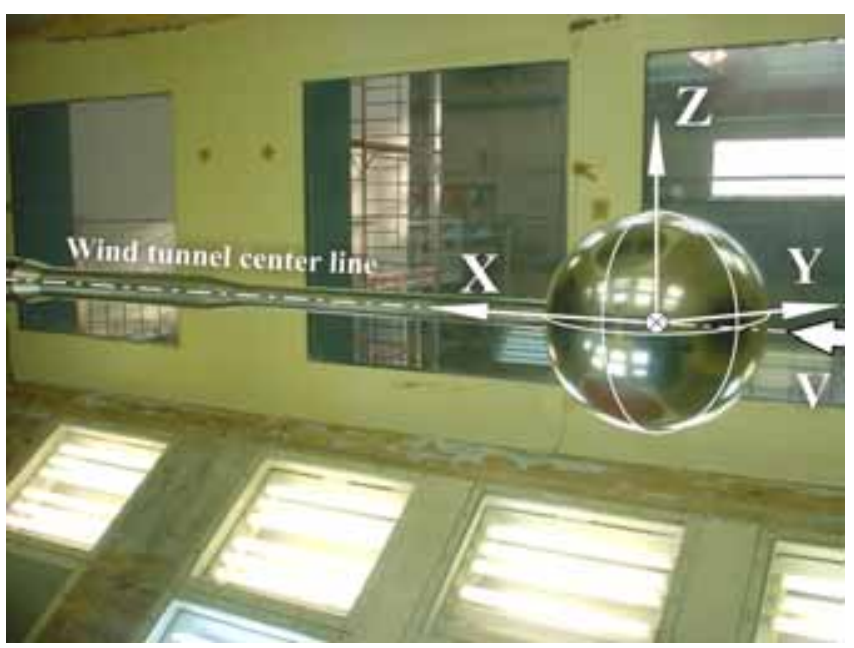

Figure 3. Pressure sphere in the T-35 test section

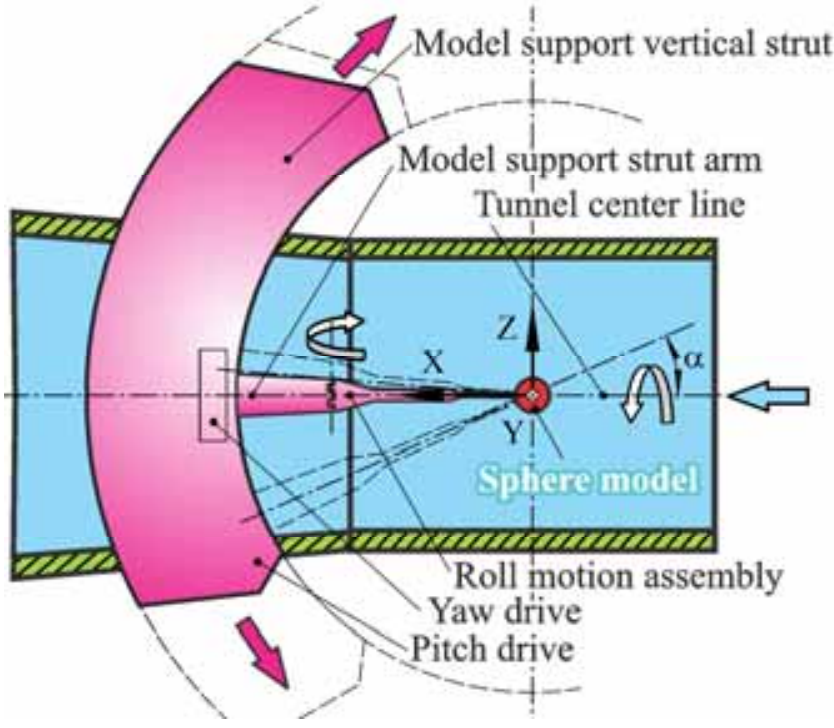

Figure 4. Model support system in the T-35

The experimental tests contained the force and moment measurements on the sphere and the flow visualization at three Mach numbers: $M=0.1 ; 0.14$ and 0.18 . Flow conditions were set, in the fan-only regime, by a power unit control system. A primary measurement system forwarded data of the flow conditions, both to the power unit control system and to a data acquisition system. Mach number and stagnation pressure regulation are better than $0.7 \%$. In general, an excellent flow quality of the T-35 is described with the following parameters: the longitudinal and transversal Mach number distributions have a standard deviation better than 0.005 and 0.006 , respectively, below $M<0.4$, while the flow direction differs about $0.1^{\circ}$. Turbulence intensity, obtained by a hot wire anemometry, is about $0.1 \%$, in a range of $M<0.5$.

For each run sequence, the force and moment measurements were done by the internal six-component VTI balance, an in-house product, whose nominal drag force range is $850 \mathrm{~N}$.

Flow visualization was done for the flow transition and flow separation estimation by using an oil emulsion technique. The holes for pressure measurements and a space near the balance were covered by the Sellotape and uniformly coated with a creamy paste of an emulsion, by a sponge, for each test run individually. The emulsion mixture consisted of $10 \mathrm{~g}$ of $\mathrm{TiO}_{2}, 30 \mathrm{~cm}^{3}$ of Kerosene and $3 \mathrm{~cm}^{3}$ of oleic acid. The pre-run coated sphere is shown in Fig.5.

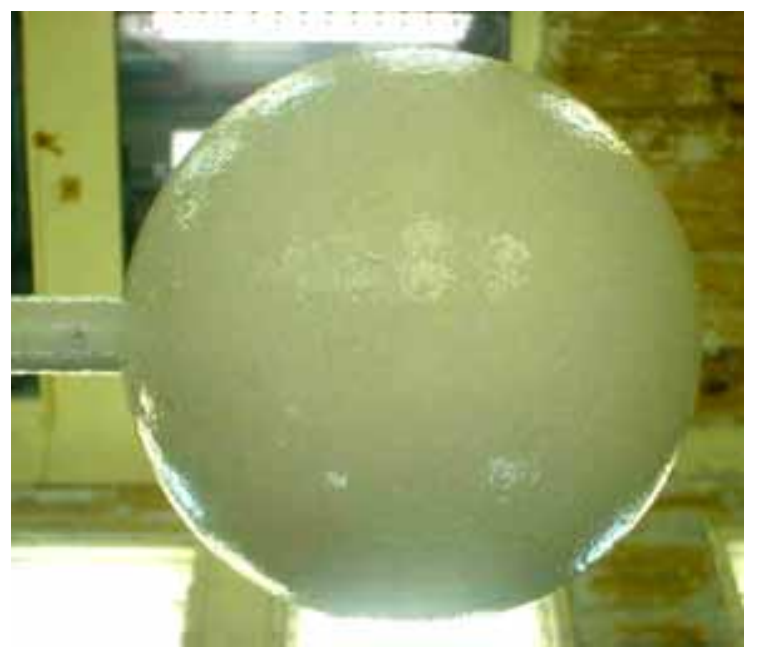

Figure 5. The sphere in the T-35 test section coated with the emulsion

Signals from all of the transducers and measuring devices 
were synchronized with the time base of the digital chronometer with the purpose of data segmenting. The data acquisition system consists of 64-channel system of the NEFF $620 / 600$ under the control of the VAX 8250 computer. Model positioning was controlled by a PC. Data reduction was also made by VAX 8250 computer using standard software for data reduction of the VTI wind tunnels.

Processed data gave the base for calculation of the flow parameters and dimensionless coefficients for the further use in the study. The drag coefficient is defined as in Eq.1

$$
C_{D}=\frac{D}{q S}
$$

Duration of the wind tunnel flow acceleration, steadying the flow and data acquisition, necessary for the force and moment measurement, was prolonged until the emulsion was almost dry. Flow traces on a surface were photographed from a close distance after the wind tunnel run.

\section{Numerical Simulations}

Numerical simulations were done by the ANSYS Fluent 12 computation fluid dynamic software. The geometry of a numerical domain and the model were prepared in the Design Modeler. The real scale model, a sphere of $110 \mathrm{~mm}$ in diameter, was placed inside the cylinder of $3 \mathrm{~m}$ in diameter and $5 \mathrm{~m}$ long. One ellipsoid-like body was constructed around the sphere to be a body of influence. By the Meshing Application the meshing operation was done with the following parameters: meshing method - automatic- patch conforming; advance size function - curvature; smoothing high; transition - fine; minimal size $-0.1 \mathrm{~mm}$; maximal face size $-95.7 \mathrm{~mm}$ and maximum tetrahedral size $-191.46 \mathrm{~mm}$; growth rate -1.2 . Inflation covered the sphere, selecting the first layer thickness option. The first layer height was $1 \mathrm{~mm}$ (to cover the double rough height); 10 layers with 1.05 growing rates. The statistical values numbered 1949508 mixed elements of the mesh, the skewness of maximum 0.79 (average 0.21) and an aspect ratio of element dimensions of 9.3. In Fig. 6 a half of the meshed domain is presented, while in Fig 7 a detail of the sphere and body of influence mesh are shown. Fig 8 details the view of the inflation layer around the rough sphere in the cross-section. The face element size over the rough sphere is $0.5 \mathrm{~mm}$ and the element size inside the body of influence is defined with $5 \mathrm{~mm}$. Values were selected after the grid independence checks except the first layer height.

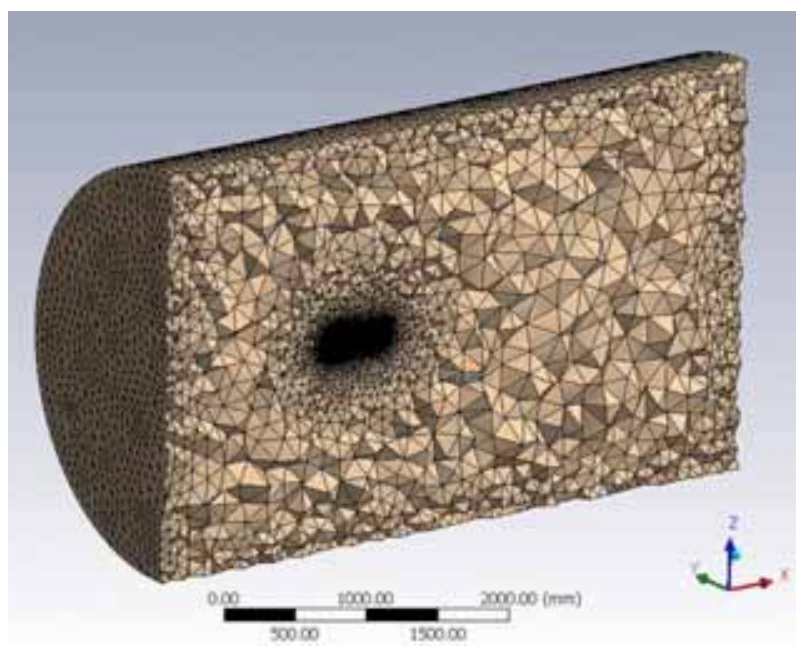

Figure 6. One half of the meshed numerical domain

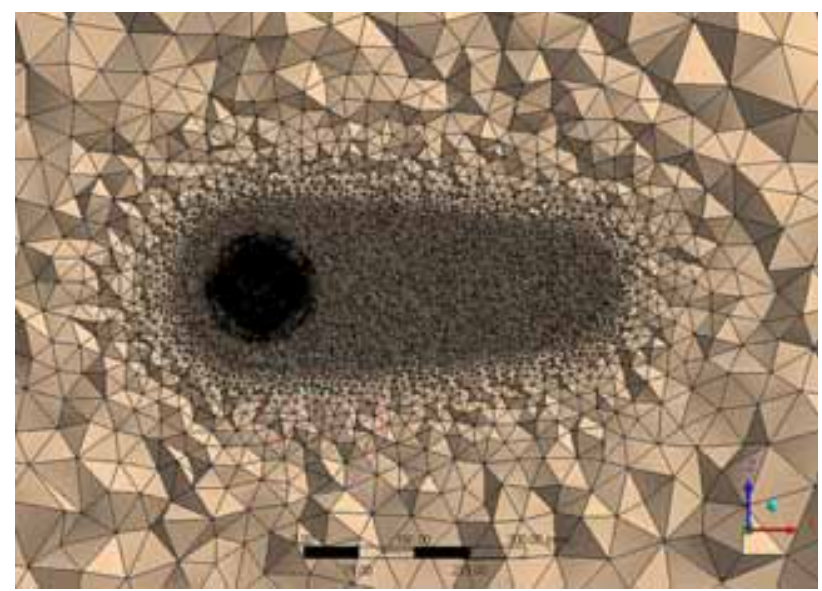

Figure 7. Meshed sphere and the body of influence

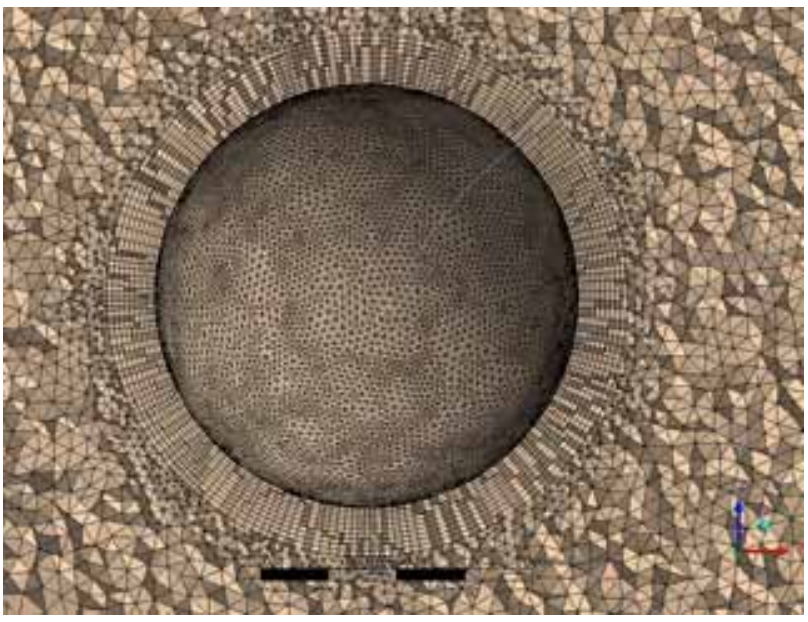

Figure 8. The rough sphere and inflation layer in cross-section

The selected absolute roughness, in each cell of the first inflation layer, according to the CFD recommendations, should be placed into a zone of the first centroid, which leads to the first layer height larger than a double roughness height (Fig.9). This condition, applied to turbulent models as a Transition SST, causes questionable results, because the basic requirements are in connection just after the height of the first inflation layer. In this work one example of this problem is presented to compare.

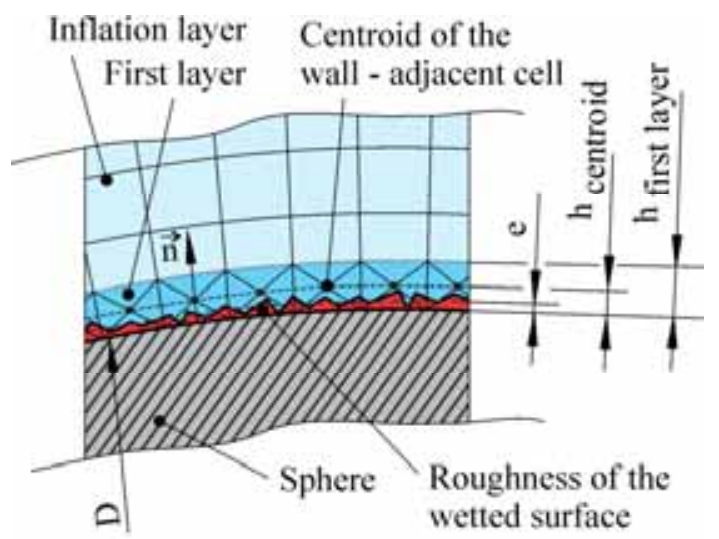

Figure 9. Geometry parameters in the inflation layer over the rough sphere

For setting the material and boundary conditions, BC, data from the wind tunnel tests were adopted as an initial guess: air properties operational and gauge pressure, temperature, flow velocity. The turbulence intensity was set for the inlet and outlet $\mathrm{BC}$ in the same manner and the sphere was defined as a wall of different absolute roughness due to cases. A cylinder 
outer surface was defined as a symmetry BC. These data were used as parameters for a discussion of the result.

Numerical simulations were steady-state, incompressible, of pressure-based type run under the same solution methods and controls. A pressure-velocity coupling scheme was PISO, for the time consumption reduction. First 60 iterations were run in the first order spatial discretization and continued with the second order. Under the relaxation the factors were as listed: pressure -0.3 , momentum -0.7 , turbulent kinetic energy -0.8 , turbulent dissipation rate 0.8 and turbulent viscosity -1 . Averaged number of iterations for all the cases was from 4000 to 6000 .

The Reynolds Averaged Navier-Stokes (RANS) turbulence model $k-\varepsilon$ Realizable, with two-layer based Non-Equilibrium wall function, was used for its benefits in solving the shear flows with a boundary-layer or a massive flow separation [26], and has a good convergence behavior and is time saving, which is important for industrial applications.

Standard $k-\omega$ is an appropriate choice in expected cases of the free shear, complex boundary layer with a reverse pressure gradient and separation as well as the early transitional flows [26]. Similar good properties shear also the Shear-Stress Transport (SST) $k$ - $\omega$ turbulent model, but its suitability degrades with a distance from the wall. Afterwards, the Transitional SST model was used as the most accurate RANS, Reynolds Stress models, for the flow separation prediction. Requirement for the accurate use of this model is referred to a wall-adjacent cell's centroid, $y+$, to be less or equal to the unit.

\section{Results and Discussion}

The presented results of the rough sphere are selected from the wide series of experiments with the pressure sphere in the wind tunnel T-35, at moderate Reynolds numbers. The smooth and rough sphere was tested in the wind tunnel while only the rough sphere was tested by the numerical simulations. Initially, the sphere tests were performed to visualize the flow pattern after drying the emulsion, while forces and moments were also measured in that phase, thus they represent the values for the rough sphere. In Fig.10 drag coefficients, from the wind tunnel tests and numerical simulations, were correlated at the equal Reynolds numbers.

The drag coefficient curve, plotted for the mirror-polished sphere (Fig.10 ), was obtained by the wind tunnel tests, under the turbulent intensity less than $0.1 \%$, while the curve (Fig.10 $\mathbf{a}$ ) refers to the rough sphere.

In the range of the MRe from 0.34 to 0.39 , the drag coefficient curve for the smooth sphere indicated the actual region of the critical flow, a segment of the drag crisis region.

However, for the wider range of MRe, from 0.28 to 0.5 , containing also the previously mentioned, the rough sphere induced, as expected, the opposite character of the flow. The values of the drag coefficients were changing in the range from $c_{D}=0.2805$, for $M R e=0.282$, to $c_{D}=0.3252$, for $M R e=0.489$ and, if joined, they would create an almost perpendicular curve to the one of the smooth sphere. Actually, the results from the wind tunnel were considered as the spot values, not joined in a function, because from the flow visualizations it may be seen that the dried coating is thinner as $M R e$ is higher. Actually, the free flow vanishing of the coating material differs from case to case, depending on an initial emulsion layer thickness, flow character and the flow velocity and duration. The measure of the coating thickness could be estimated only by a visual inspection, because of the softness and non-uniformity of the coating structure over the sphere wetted surface.
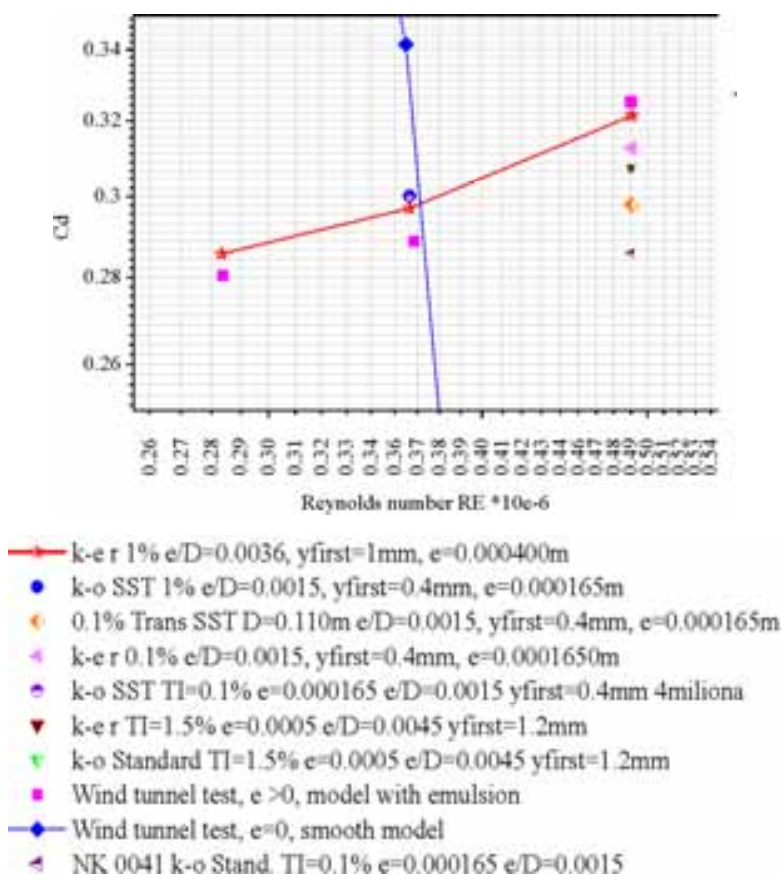

Figure 10. Drag coefficient vs. Reynolds number diagram from the wind tunnel and numerical simulation tests

Further on, comparing the relation of values of the smooth (Fig.10 ) and rough (Fig.10 a) sphere, it was indicated that while the smooth sphere experienced the sudden drag reduction, induced by the transition from the laminar to turbulent flow, followed with the delayed and unstable separation, the rough sphere experienced super-critical flow with a slight increase of the drag coefficient with $M R e$. By that means, it was indicated that the critical drag region, of the rough sphere, was displaced to a region of significantly lower $M R e$, in relation to the smooth sphere. The pressure drop occurred and the flow, at selected $M R e$, was fully turbulent, not only in the wake, but also in the boundary layer of the sphere.

From the front side of the sphere, the suspension left the deposit with winding and crossing troughs, which indicated the turbulent flow character in a local boundary layer. Opposite, on the rear side the deposit was uniformly distributed, which indicated the presence of the stabile reverse turbulent flow. Naturally, these flow behaviours were expected, due to the fact that after the sphere experienced super-critical flow, the wake consisted of a large number of smaller vortices, mutually interacting as well with the surrounding flow while forming a sort of a wake tube.

The flow visualization images in Figures 11-13 were shown for three different test cases, in accordance with the measurements of the smooth sphere, at the velocities of $M=0.1,0.14$ and $0.18(M R e=0.282,0.362$ and 0.489), respectively. Freeze flow patterns on the photos, made after the wind tunnel stopped, evidenced polar angles of the flow separation of approximately $\varphi_{W T} \approx 105^{\circ}, 110^{\circ}$ and $115^{\circ}$, in order for listed MRe. In figures a zone of the ordered flow traces may be seen, from the stagnation point to the nearness of the separation zone, the zone of the separation and a zone of the wake initialization. The zone of the transition is hardly defined because of the structure of the coating. A flow character changes in some elements from one of the smooth sphere, but it still represents the key points. Wavy separation line occurred mostly because of the roughness and imperfections in the coating thickness produced by depositions of $\mathrm{TiO}_{2}$ emulsion. Wave trace left uniformly covered rear surface of the sphere that showed the uniform 
turbulent flow in the wake. As the emulsion was applied by hand for each wind-on phase, the differences in a coating thickness affected the resulted thickness of the coating from the test, but even so they did not change key data significantly, but influenced the wind-on duration needed for emulsion drying.

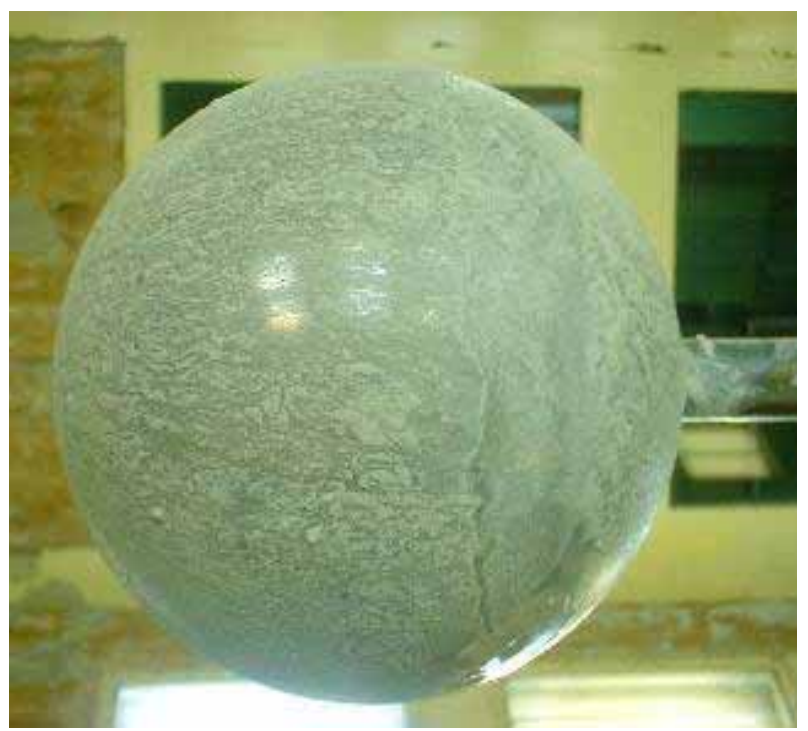

Figure 11. Flow visualization with oil emulsion at $M=0.1$

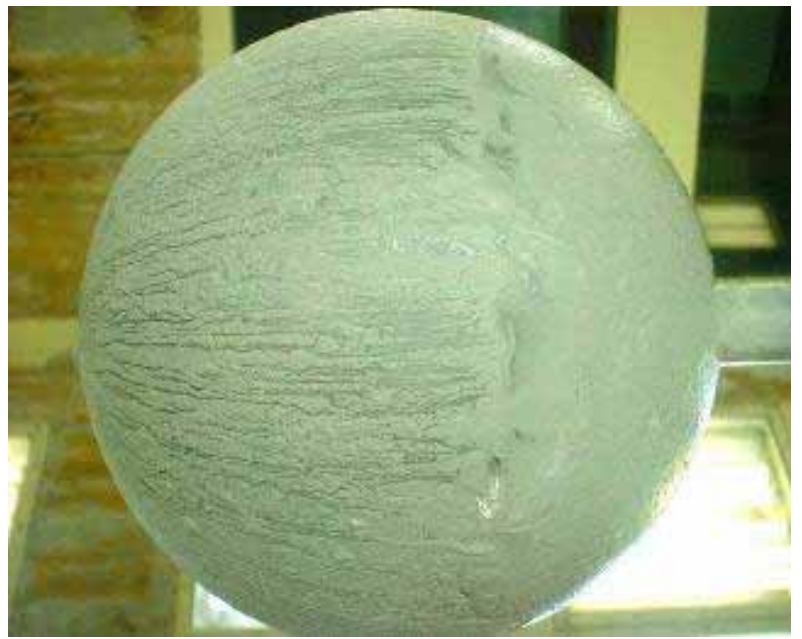

Figure 12. Flow visualization with oil emulsion at $M=0.14$

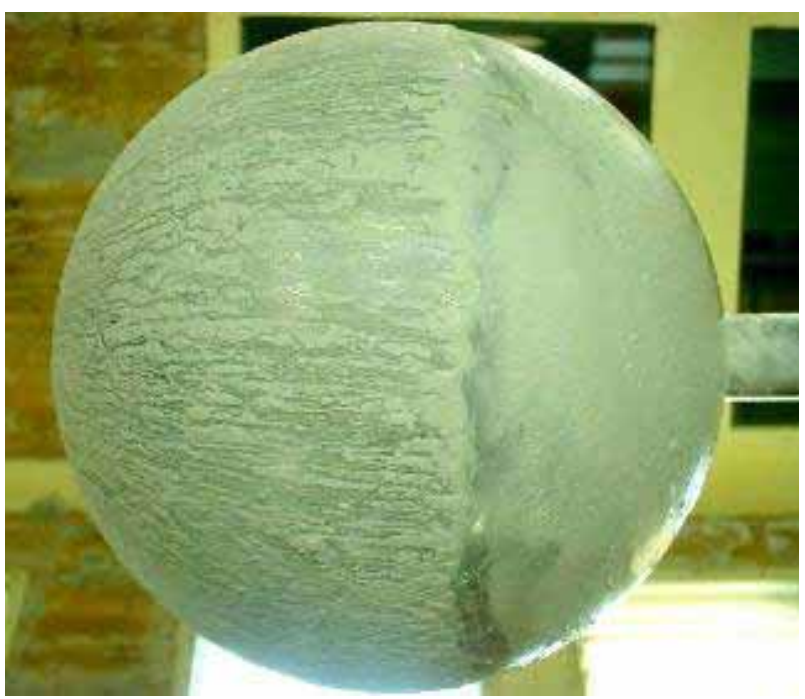

Figure 13. Flow visualization with oil emulsion at $M=0.18$
Throughout the numerical examination of the flow around the rough sphere and verification by the wind tunnel tests the following parameters were varied: surface roughness, $e$; inlet and outlet velocity, $V$, and turbulence intensity, $T u$. Turbulent models in use were k- $\varepsilon$ Realizable, $k$ - $\omega$ Standard and SST and Transitional SST (please see Table 1 with the illustrated differences between numerical and experimental data).

The influence of the inlet turbulence intensity, from the entire three test Reynolds numbers, was assumed to be the smallest at the largest velocity $(M R e=0.489)$ and for that condition a number of parameter settings were combined. The idea, in the base, is similar to intentionally induce transition in a boundary layer over the model in the wind tunnel by additional devices. Hence, in case of a numerical examination of the sphere we had the advantage to vary the turbulence intensity level and the roughness height; these were used as numerical devices for controlling the flow similarity to wind tunnel ones. The coating discontinuity was represented through the roughness height averaged in value over the surface.

The combination of the parameters did not restrict the use of the non-realistic cases, hence the simple coping of the wind tunnel flow and model parameters was not expected to be given the good correlation of the results, in the first place because of the roughness definition in both cases and also the requirements for the $y+$ witch dictated the height of the first layer of an inflation. In other words, in the presence of a roughness the requirements of the turbulence models for the first layer height could not be met simultaneously.

Table 1. Comparison of the numerical and wind tunnel results, $M R e=0.489$

\begin{tabular}{||c|c|c|c|c|c||}
\hline Test & $\mathbf{1}$ & $\mathbf{2}$ & $\mathbf{3}$ & 4 & 5 \\
\hline \hline RSN & \multirow{2}{*}{ NK 004 } & MK 006REZ & NKX 800 & MK 008REZ & \multirow{2}{*}{ NK 006 } \\
\hline$M R e$ & 0.489 & 0.489 & 0.489 & 0.489 & 0.489 \\
\hline$V[\mathrm{~m} / \mathrm{s}]$ & 66 & 66 & 66 & 66 & 66 \\
\hline Turb. model & Trans SST & $k-\varepsilon$ Realiz. & $k-\varepsilon$ Realiz. & $k$ - $\omega$ Stand. & $k-\varepsilon$ Realiz. \\
\hline$T I[\%]$ & 0.10 & 1.50 & 0.10 & 1.50 & 1 \\
\hline$\varepsilon[\mathrm{m}]$ & 0.000165 & 0.0005 & 0.000165 & 0.0005 & 0.0004 \\
\hline$\varepsilon / D$ & 0.0015 & 0.0045 & 0.0015 & 0.0045 & 0.0036 \\
\hline$y_{\text {first }}[\mathrm{mm}]$ & 0.0004 & 1.2000 & 0.0004 & 1.2000 & 1.0000 \\
\hline$c_{D}$ & 0.2979 & 0.3074 & 0.3127 & 0.3072 & 0.3214 \\
\hline$\Delta c_{D}$ & -0.02727 & -0.0178 & -0.01247 & -0.0182 & -0.0038 \\
\hline$\Delta c_{D}[\%]$ & $\mathbf{- 8 . 3}$ & $\mathbf{- 5 . 4}$ & $\mathbf{- 3 . 8}$ & -5.5 & -1.1 \\
\hline \hline
\end{tabular}

Table 2. Comparison of the numerical and wind tunnel results for $M R e=$ $0.282,0.362$ and 0.489

\begin{tabular}{|c|c|c|c|}
\hline Test & $\overline{5}$ & 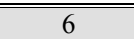 & 7 \\
\hline$\overline{\mathrm{RSN}}$ & NK 006 & NK 200 & NK 300 \\
\hline$M R e$ & 0.489 & 0.362 & 0.282 \\
\hline$V[\mathrm{~m} / \mathrm{s}]$ & 66 & 48 & 37 \\
\hline$M$ & 0.18 & 0.14 & 0.1 \\
\hline Turb. model & $k-\varepsilon$ Realiz. & $k-\varepsilon$ Realiz. & $k-\varepsilon$ Realiz. \\
\hline$T u[\%]$ & $1 \%$ & $1 \%$ & $1 \%$ \\
\hline$e[\mathrm{~m}]$ & 0.0004 & 0.0004 & 0.0004 \\
\hline$e / D$ & 0.0036 & 0.0036 & 0.0036 \\
\hline$y_{\text {first }}[\mathrm{mm}]$ & 1.0000 & 1.0000 & 1.0000 \\
\hline \multicolumn{4}{|l|}{$y^{+}$} \\
\hline$c_{D}$ & 0.3214 & 0.2970 & 0.2857 \\
\hline$c_{D W T}$ & 0.3252 & 0.2888 & 0.2805 \\
\hline$\Delta c_{D}$ & -0.0038 & 0.0082 & 0.005 \\
\hline$\Delta c_{D}[\%]$ & -1.1 & 2.8 & 1.8 \\
\hline$\varphi_{W T}[\mathrm{deg}]$ & $\approx 105$ & $\approx 110$ & $\approx 115$ \\
\hline$\varphi[\mathrm{deg}]$ & 99 & 102 & 104 \\
\hline$\Delta \varphi[\mathrm{deg}]$ & 6 & 8 & 11 \\
\hline$\Delta \varphi[\%]\left(\right.$ of $\left.180^{\circ}\right)$ & $\approx 3$ & $\approx 4$ & $\approx 6$ \\
\hline
\end{tabular}

The criteria of selecting the most successful combination of parameters was the flow field similarity, represented by the velocity vector distribution, wall shear stress and pressure 
distribution, and the values of the drag coefficient. Comparison of the numerical and wind tunnel results, $M R e=0.489$ are shown in Table 1 . After selecting the combination of parameters for the highest Reynolds number, from Table 1, those were adopted and for the two other tests, for the lower Reynolds numbers, whose results are presented in Table 2.

From Fig. 10 and Table 1 it may be seen that the closest value of the drag coefficients, at $M R e=0.489, M=0.14$, was obtained in value of about $1 \%$, for the combination of $k-\varepsilon$ Realizable model, turbulence intensity about $1 \%$, relative roughness of $e / D=0.0036$ and the first inflation layer thickness of $1 \mathrm{~mm}$. Other combinations in results gave differences from $3.8 \%$ to $8.3 \%$, which are unacceptable. Large differences in drag coefficients are originated because the roughness height defined a height of the first layer. The Transitional SST turbulent model, which, commonly, is successfully solving the cases with a flow separation, under the condition of the smooth models, appeared to be inappropriate in the cases of rough models. The industrial $k-\varepsilon$ Realizable model gave, in this examination, a better global perception of the flow around the sphere. One should be careful in reading the results, keeping the awareness that the images of the flow field around the rough sphere, under the selected conditions, from the stagnation point are not presenting the laminar flow as well as that the wake is not presented realistically - as highly turbulent flow, but with tidy and symmetrical streamlines. The origin lies in the numerical method.

In the case of $M R e=0.362, M=0.11$, from Fig.10, less combinations were applied, according to previous experiences. The similar results were obtained but now the difference in drag coefficients between the best combination and the wind tunnel is larger in comparison to $\mathrm{MRe}=0.489$. Other combinations, from Fig.10, showed more concentrated results, but targeted over the wind tunnel values.

For the test with the $M R e=0.281, M=0.1$, only one parameter combination was used to check the trend of the drag coefficient changes.

Actually, we made an attempt to predict the best combination of the parameters by a simple linearization of variable parameters, as shown in Fig.14. Following the trend of a drag coefficient variation, with the $M R e$ and roughness height, the aim was to intentionally produce the flow in numerical domain that would be similar to real and lead to drag coefficient obtained in the wind tunnel. Hence, this way did not give the expected results, but on the contrary, a significant lost occurred.

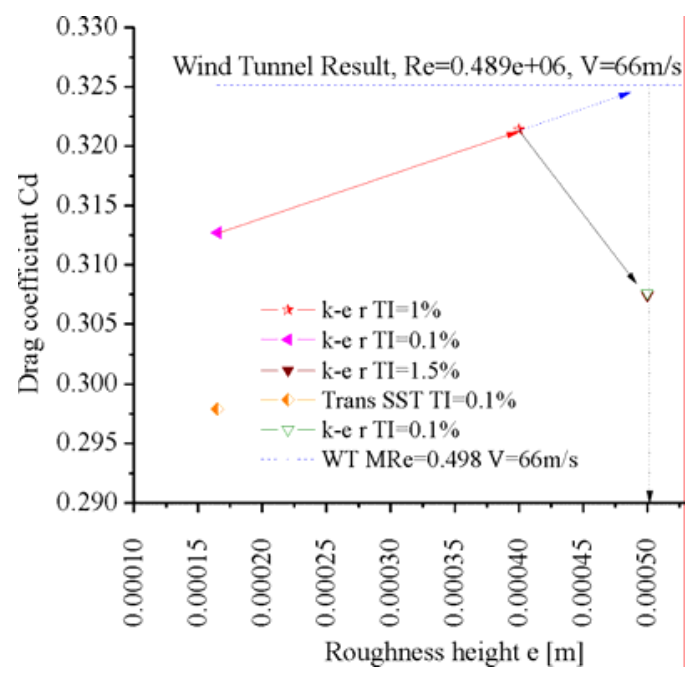

Figure 14. Drag coefficient as a function of roughness height obtained for different turbulent models and turbulent intensities
The curve, spline over the results for the combination of $k$ - $\varepsilon$ Realizable model, turbulence intensity about $1 \%$, relative roughness of 0.0036 and the first inflation layer thickness of $1 \mathrm{~mm}$, followed the trend of a drag coefficient of the rough sphere in the wind tunnel, for the equal $M R e$, turbulence intensity of $0.1 \%$ and estimated roughness heights.

The polar angles at which the flow separates from the sphere surface, $\varphi$, in numerical simulations, were extracted from the first minimum of a skin friction coefficient over the sphere in longitudinal cross section (only a half of the sphere was observed for this purpose assuming symmetry in a steady flow). The comparison of the polar angles of the flow separation obtained numerically, $\varphi$, is given in Table 2 , and is in a good agreement to the flow visualizations, $\varphi_{W T}$.

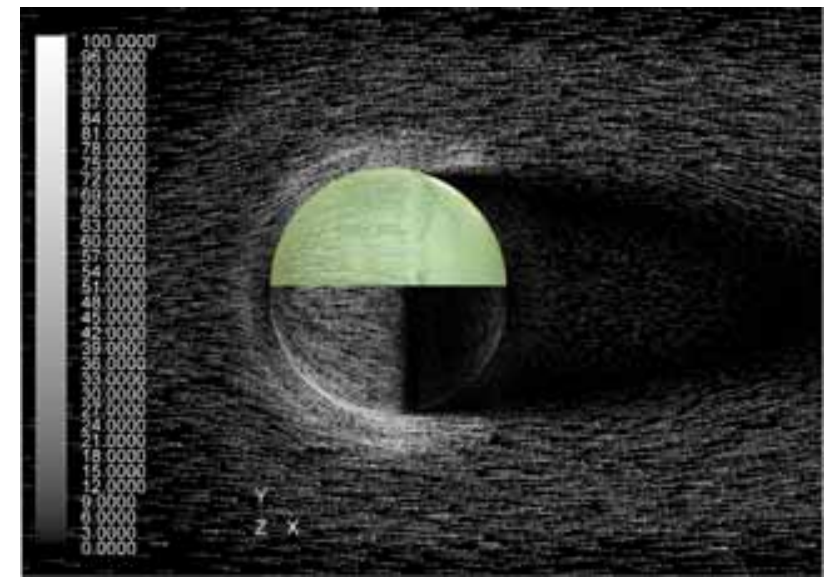

Figure 15. Overlap of the velocity vectors (Test 5 ) and the visualization at $M R e=0.489, M=0.18$

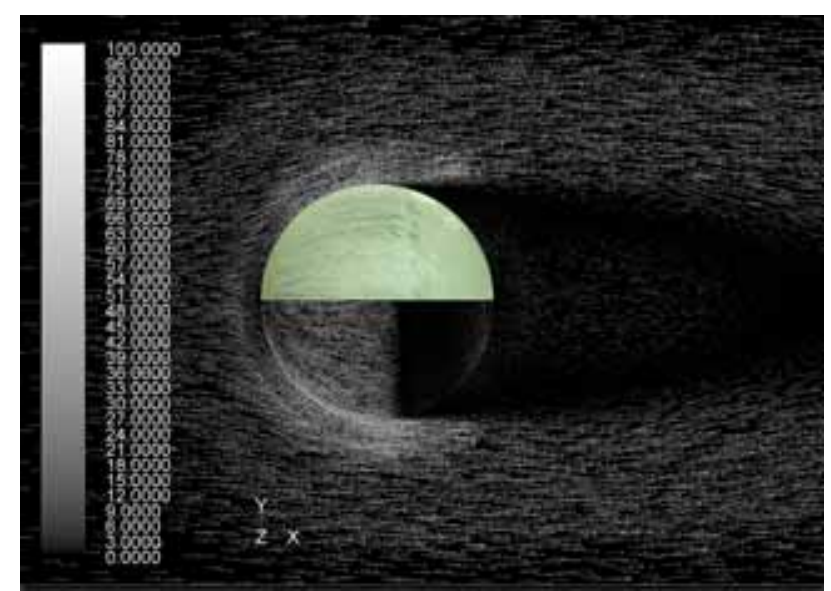

Figure 16. Overlap of the velocity vectors (Test 6 ) and the visualization at $M R e=0.362, M=0.14$

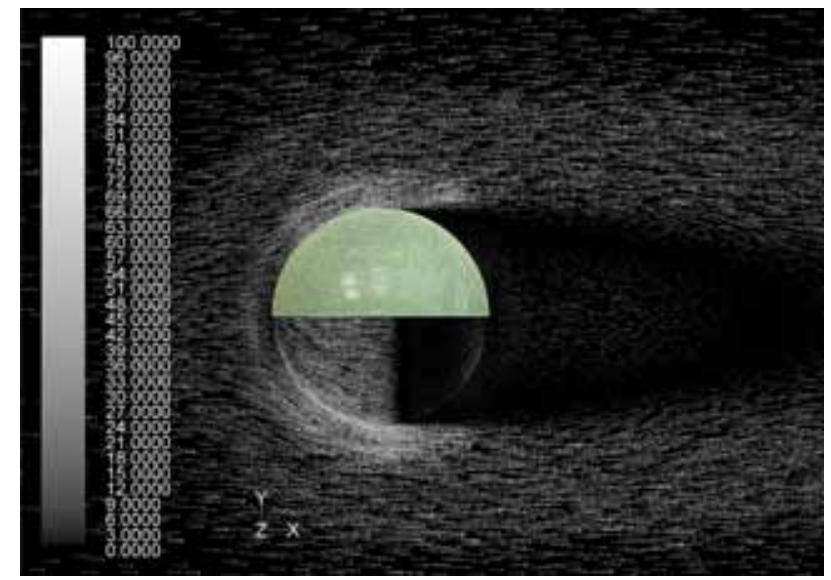

Figure 17. Overlap of the velocity vectors (Test 7) and the visualization $M R e=0.281, M=0.1$ 
Increasing the Reynolds number, the results of the numerical simulations are closer to the wind tunnel's, described by differences of $\varphi$, from $6 \%$ to $3 \%$ of a half-circle. However, these results are presented in comparisons of the velocity vectors against the flow visualization images, for three $M R e=0.1 ; 0.14 ; 0.18$ in Figures $15-17$ respectively. Even the flow fields' representations could not bring the exact values and relations; they confirmed the calculated results from the Table 2.

The used surface visualization method is very descriptive for the flow quality investigation at the test section, giving the valuable confirmation of the numerical results, while it is not expected to answer to the requirements of testing of the rough sphere.

It may be seen from the numerically estimated drag coefficients and the pressure distribution, in Fig.18, that the sphere, at $M=0.1,0.14$ and 0.18 , is experiencing the turbulent flow, in the super-critical regime when the pressure in the sphere wake is recovering. For the selected boundary conditions and the roughness, numerical simulations predicted the flow well. Here, one may note that the used steady-state flow type in a combination with the RANS turbulent models are not able to predict the turbulent flow inside the wake, just the averaged values are available, but the key flow parameters are in a good agreement with the wind tunnel results. A more detailed study requires significantly larger resources.

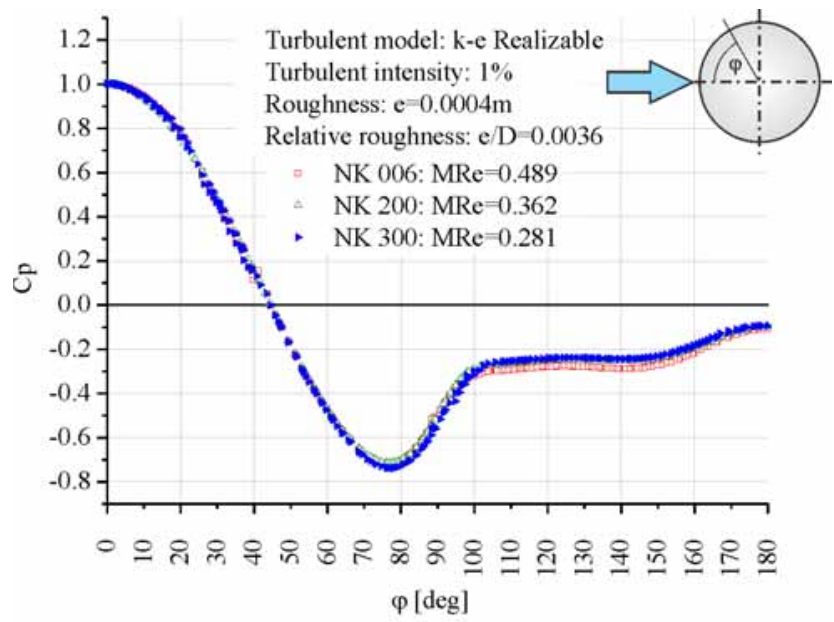

Figure 18. Pressure coefficient around the longitudinal half cross section obtained by the use of $k-\varepsilon$ Realizable turbulent model, $T u=1 \%$ and $e / D=0.0036$, at $M R e=0.281,0.362$ and 0.489

Furthermore, one may note a support-free configuration of the sphere in the numerical study. Introduction of the sting support was made to the level of the mesh when the number of elements increased to a number that can not be handled by the Solver, on the current resource. The absence of the sting support in a part resulted in the difference of the flow patterns and flow parameters of the numerical study in comparison to the wind tunnel data. So, it was assumed, according to the experience, that sting support system is introducing flow disturbance, especially in the range of critical Reynolds numbers, but numerically obtained differences are acceptable for the practical implementation of the presented results.

\section{Concluding Remarks}

The obtained differences of the results from the wind tunnel and numerical simulations are in the range of the engineering applications, but for the more detailed prediction of the flow in further studies, it is recommended to test the sphere in the wind tunnel covered with a fixed Carburundum coating, of different grains, and in a wider range of the Mach numbers. Also, for further studies, the VTI intern-facilities tests and implementation of different measuring and visualization techniques will make a larger data base from which further numerical investigations and adjustments may be started.

As shown by the results, the turbulence model which accuracy was expected to be the highest, Transitional SST, as in the case of smooth models, in case of the rough models its applicability is restricted because of the high requirements of the numerical model that could not be reached.

Furthermore, the method of the emulated flow condition, under a criterion of reaching the flow similarity, by the selection of non-existed roughness and turbulent intensity, is applicable to the other objects, even assuming the higher level of accuracy, because of the fact that all the other streamlined and blunt bodies are less sensitive to the flow changes. Of course, for the practical problems which do not allow the fully experimental testing, the numerical simulations can be used as a confident extension tool, while in future researches a development of the additional numerical tools will help a closer prediction of the complex flows over the rough surfaces. In addition, the future numerical studies will examine the influence of the sting support on the flow over the rough sphere.

\section{Acknowledgements}

The authors express their sincere thanks to the Ministry of Education, Science and Technological Development of the Republic of Serbia, for the financial support through the TR35045, TR-35046 and TR-34028 (2011.- 2015.) projects.

The authors also express their gratitude to the Experimental Aerodynamic Laboratories of the Military Technical Institute, VTI, Belgrade, its management and staff for the support and execution of the experimental part of this research.

\section{References}

[1] RIABOUCHINSKY,D.P.: On the Resistance of Spheres and Elipsiods in Wind Tunnels, NACA Technical Note No.44, 1921.

[2] KRUMINS,M.V.: A Review of Sphere Drag Coefficient Applicable to Atmospheric Sensing, NOLTR-72-34, Naval Ordnance Laboratory Silver Spring, Maryland, 1972.

[3] ZXHM, A.F.: Flow and Drag Formulas for Simple Quadrics, NACA Report No. 253, 1927.

[4] WIESELSBERGER,C.: New Data on the Laws of Fluid Resistance, NACA No.84, 1922.

[5] SCHLICHTING,H.: Boundary-Layer Theory, 7th edn., McGraw-Hill, New York, 1979, ISBN 0-07-055334-3.

[6] ACHENBACH,E.: Experiments on the flow past spheres at very high Reynolds numbers, Journal of Fluid Mechanics, 1972, 54, pp. 565-575, doi:10.1017/S0022112072000874.

[7] ACHENBACH,E.: The Effiects of Surface Roughness and Tunnel Blockage on the Flow Past Spheres, Journal of Fluid Mechanics, 1974, 65, part I, pp 113-125.

[8] BATCHELOR,G.K.: An Introduction to Fluid Dynamics, Cambridge University Press , 2002, ISBN 0-521-66396-2, UK.

[9] HOERNER,S. : Tests of Spheres with Reference to Reynolds number Turbulence and surface roughness, NACA TM 777, 1935.

[10] CONSTANTINESCU,G., CHAPELET,M., SQUIRES,K.: Turbulence Modeling Applied to Flow over a Sphere, AIAA Journal, 2003, 41 (9), pp.1733-1742.

[11] CONSTANTINESCU,G., SQUIRES,K.: Numerical investigations of flow over a sphere in the subcritical and supercritical regimes, Physics of Fluids, 2004; Vol.16, No.5, DOI: 10.1063/1.1688325.

[12] JONES,D.A., CLARKE,D.B.: Simulations of Flow Past Sphere using a Fluent Code, DSTO-TR-2232, Australian Government, Department of Defence, Maritime Platforms Division, Defence Science and Technology Organisation Australia, 2008. 
[13] FORNBERG,B.L.: Steady viscous flow past a sphere at high Reynolds numbers, Journal of Fluid Mechanics, 1988, 190, pp. 471-489, DOI:10.1017/S0022112088001417.

[14] MEHTA,R., PALLIS, J.M.: Material and Science in Sports.Dynamics: Sport Ball Aerodynamics: Effects of Velocity, Spin and Roughness, TMS, 2001, pp. 185-197.

[15] CROSS,R.: Sports ball aerodynamics, Physics Department, University of Sydney, http://www.physics.usyd.edu.au/ cross/TRAJECTORIES/ Sports\%20Balls.pdf.

[16] KENSRUD,J.R.: Determining Aerodynamic Properties of Sports Balls in Situ, MSc Thesis, Washington State University, Department of Mechanical ans Materials Engineering, August 2010. http://baseball.physics.illinois.edu/KensrudThesis.pdf.

[17] TANEDA,S.: Flow Visualization-Scientific Images, SciPress, Tokyo, Japan, 2000. ISBN 4-88704-126-8

[18] CROSS,R.: Wind Tunnel Photographs, Physics Department, University of Sydney, http://www.physics.usyd.edu.au/ cross/TRAJECTORIES/ Fluidflow\%20Photos.pdf.

[19] RISTIĆ,S.: Flow Visualisation Techniques in Wind Tunnels Part INon optical Methods, Scientific Technical Review, ISSN 1820-0206, 2007, Vol.57, No.1, pp.39-49.

[20] RISTIĆ,S.: Flow visualization techniques in wind tunnels-optical methods (Part II), Scientific Technical Review, ISSN 1820-0206, 2007, Vol.57, No.2, pp.38-49.

[21] RISTIĆ,S.: A View in the Invisible, Theoret.Appl.Mech.TEOPM7, Belgrade, Serbia, 2013, Vol. 40, No. 1, pp.87-119.

[22] RISTIĆ,S.: Vizuelizacija strujanja oko kugle metodom uljanih emulzija $u$ aerotunelu T-35, VTI, 2004.

[23] ČANTRAK,Đ., JANKOVIĆ,N., RISTIĆ,S., ILIĆ, D.: Influence of the Axial Fan Blade Angle on the Turbulent Swirl Flow Characteristics, Scientific Technical Review, ISSN 1820-0206, 2014, Vol. 64, No. 3, pp.23-30.

[24] ANDERSON, T.J., UHLHERR, P.H.T.: The Influence of Stream Turbulence on the Drag of Freely Entrained Spheres, 6th Australasian Hydraulics and Fluid Mechanics Conference, Adelaide, Australia, 5-9 December 1977.

[25] TERWAGNE,D., BROJAN,M., REIS,P.M.: Smart Morphable Surfaces for Aerodynamic Drag Control, Adv. Mater.2014, WILEYVCH Verlag GmbH \& Co. KGaA, Weinheim, 2014., pp. 1-4. DOI: 10.1002/adma.201401403

[26] ANSYS Fluent 12 Documentation

\title{
Eksperimentalno i numeričko istraživanje nadkritičnog strujanja oko hrapave kugle
}

\begin{abstract}
Rad predstavlja eksperimentalno i numeričko istraživanje modela sfere sa ciljem predviđanja ponašanja strujanja u prisustvu hrapavosti površina. Rezultati ukazuju na probleme i predlažu rešenje za inžinjersku primenu. Sličnost između strujnih slika dobijenih numeričkim putem i u aerotunelu je postignuta kombinovanim uvođenjem turbulencije u numeričkoj slobodnoj struji hrapavosti površine, zbog ograničavajućih zahteva turbulentnih modela.
\end{abstract}

Ključne reči: aerodinamika, aerodinamički tunel, numerička simulacija, sfera, hrapava površina, strujanje fluida

\section{Экспериментальное и численное исследование сверхкритического обтекания шероховатых шаров}

\begin{abstract}
Эта статья представляет собой экспериментальное и численное исследования модели сферы с целью прогнозирования поведения потока в присутствии неровностей поверхности. Результаты указывают на проблемы и предлагают решения для практического инженерного применения. Сходство между текущими изображениями, полученными численным моделированием и в аэродинамической трубе достигается за счёт смешанного введения турбулентности в численном свободном потоке и шероховатости поверхности, из-за ограничительных требований турбулентных моделей.
\end{abstract}

Ключевые слова: аэродинамика, аэродинамическая труба, численное моделирование, сферы, неровная поверхность, поток жидкости.

\section{Recherches expérimentales et numériques du courant super critique autour d'une sphère rugueuse}

\begin{abstract}
Ce travail présente les recherches numériques et expérimentales du modèle de sphère afin de prévoir le comportement du courant dans la présence des surfaces rugueuses. Les résultats obtenus indiquent les problèmes et proposent les solutions pour l'application dans l'ingénierie. La similitude entre les images de mouvement obtenues par la voie numérique ainsi que dans la soufflerie aérodynamique a été réalisée en combinant l'introduction de la turbulence dans le courant numérique libre et la surface rugueuse à cause des exigences limitées des modèles turbulents.
\end{abstract}

